\title{
Graphite-anchored lithium vanadium oxide as anode of lithium ion battery
}

Jin Yi, Julian Key, Fei Wang, Yonggang Wang, Congxiao Wang and Yongyao Xia

\begin{abstract}
Graphite-anchored lithium vanadium oxide ( $\left.\mathrm{Li}_{1.1} \mathrm{~V}_{0.9} \mathrm{O}_{2}\right)$ has been synthesized via a "one-pot" in situ method. The effects of the synthesis conditions, such as the ratio of reaction components and calcination temperature, on the electrochemical performance are systematically investigated by means of scanning electron microscopy (SEM), X-ray diffraction (XRD), electrochemical impedance spectroscopy (EIS), galvanostatic discharge/charge tests and differential scanning calorimetry (DSC). Compared with the simple mixture of graphite and lithium vanadium oxide, the graphite-anchored lithium vanadium oxide delivers an enhanced reversible capacity, rate capability and cyclic stability. It also shows better thermal stability.
\end{abstract}

\section{Introduction}

With recent advances in electronic devices, anode materials with high storage capacity and high power density attract considerable interest as alternatives to the commercial graphite anode used in lithium ion batteries [1,2]. The layered structured lithium vanadium oxide $\left(\mathrm{Li}_{1.1} \mathrm{~V}_{\mathrm{O}} . \mathrm{O}_{2}\right)$, has a low working potential of approximately $0.1 \mathrm{~V}$ vs. $\mathrm{Li}^{+} / \mathrm{Li}$, with a gram specific capacity of, $(314 \mathrm{mAh} / \mathrm{g}$ ) similar to graphite $(372 \mathrm{mAh} / \mathrm{g})$, but shows a higher volumetric capacity density of $1360 \mathrm{mAh} / \mathrm{cm} 3$ (790 $\mathrm{mAh} / \mathrm{cm} 3$ for graphite), and is therefore of considerable interest as an anode material [3,4]. However, its use is inhibited by its large volume expansion during $\mathrm{Li}$ intercalation, which causes particle fracture and a subsequent decay of capacity [5].

Due to the similar lithium intercalation voltage of graphite and lithium vanadium oxide, the two materials are usually mechanically mixed to form a mixture anode that has a higher volumetric energy density than pure graphite and better cyclic performance than pure lithium vanadium oxide [6]. However, the mixture still lacks sufficient reversible capacity and cyclic performance, most likely due to a loss of contact between the graphite and lithium vanadium oxide during cycling. In this work, we reported a graphite-anchored lithium vanadium oxide complex (GA-LVO) synthesized using a "one-pot" in situ method to improve the contact between the graphite and lithium vanadium oxide. The effects of the synthesis conditions, including the ratio of reaction components and calcination temperature, 
on the electrochemical performance of the GA-LVO were investigated. Carboncoating technology was applied to enhance the reversible capacity and cycling stability.

\section{Experimental}

\subsection{Chemicals and synthesis}

Graphite-anchored lithium vanadium oxide (GA-LVO) was synthesized by mixing $\mathrm{V}_{2} \mathrm{O}_{3}$ (Aldrich, 98\%) and $\mathrm{Li}_{2} \mathrm{CO}_{3}$ (Alfa Aesar, 99.99\%) in a molar ratio of 1.1: 0.9 (Li to V) with natural graphite (Superhoo Co., Ltd., Yunan). The mixtures were ball-milled in a planetary ball mill at 350 rpm for $6 \mathrm{~h}$ under argon protection. The ball-milled powders were then sintered at $850{ }^{\circ} \mathrm{C}$ or $1100{ }^{\circ} \mathrm{C}$ for $12 \mathrm{~h}$ under flowing $\mathrm{Ar}$ gas containing $5 \%(\mathrm{v} / \mathrm{v}) \mathrm{H}_{2}$ and cooled to room temperature. A series of GA-LVO samples with different ratios of LVO to graphite were prepared by the same synthesis processes. For comparison, pure $\mathrm{Li}_{1.1} \mathrm{~V}_{0.9} \mathrm{O}_{2}$ (P-LVO) was synthesized under the same conditions without graphite addition.

A carbon coated GA-LVO (C-GA-LVO-1) sample was prepared by the following process: $4 \mathrm{~g} \mathrm{GA}-\mathrm{LVO}-1$ powder (see above) was added to a $100 \mathrm{ml}$ ethanol solution containing $10 \mathrm{wt} \%$ sucrose (relative to the GA-LVO-1 powder) and stirred for $1 \mathrm{~h}$. The mixture was dried at $80{ }^{\circ} \mathrm{C}$ for $24 \mathrm{~h}$. The dried powder was ground, sintered at $750{ }^{\circ} \mathrm{C}$ for $10 \mathrm{~h}$ under flowing Ar gas containing $5 \%(\mathrm{v} / \mathrm{v}) \mathrm{H}_{2}$, room temperature.

\begin{tabular}{|c|c|c|c|}
\hline Sample & $\begin{array}{l}\text { Mass ratio: } \\
\text { graphite:LVo }\end{array}$ & $\mathrm{T}\left({ }^{\circ} \mathrm{C}\right)$ & Method \\
\hline GA-LVO-1100 & $1: 1$ & 1100 & "One pot" \\
\hline P-LVO & $0: 1$ & 850 & \\
\hline GA-LVO-0.5 & $0.5: 1$ & & \\
\hline GA-LVO-1 & $1: 1$ & & \\
\hline GA-LVO-2 & $2: 1$ & & \\
\hline C-GA-LVO-1 & $1: 1$ & 850 and 750 & $\begin{array}{l}\text { "One pot" and carbon } \\
\text { coating }\end{array}$ \\
\hline MG-LVO & $1: 1$ & 850 & Ball milling \\
\hline
\end{tabular}

For comparison, a mixture of P-LVO and natural graphite (MG-LVO) was prepared by the ball-milling process in a planetary ball mill at $350 \mathrm{rpm}$ for $6 \mathrm{~h}$ under argon protection. The preparation conditions for all samples are summarized in Table 1.

\subsection{Characterization}

The particle size and morphology were characterized using a JEOL JSM6390 scanning electron microscope (SEM). X-ray powder diffraction (XRD) patterns were recorded on a Bruker D8 X-ray diffractometer at a scan rate of $0.02{ }^{\circ} \mathrm{s}^{-1}$ using $\mathrm{Cu} \mathrm{Ka}$ radiation $\left(,=1.5406 \mathrm{~A}^{\circ}\right.$ ).

\subsection{Electrochemical tests}

The working electrodes were prepared by mixing 90\% of the sample powders, $5 \%$ carbon black and 5\% polyvinylidene fluoride (PVDF) dissolved in N-methylpyrrolidone (NMP), and the slurries were coated on copper foil using the doctor- 
blade technique. The electrode films were dried at $80{ }^{\circ} \mathrm{C}$ for $2 \mathrm{~h}$ to remove the solvent before pressing. The electrode film was punched in the form of disks, typically with a diameter of $12 \mathrm{~mm}$, and then dried at $80^{\circ} \mathrm{C}$ for $12 \mathrm{~h}$ under vacuum. The typical mass loading of the active material of the working electrodes was approximately $5 \mathrm{mg}$. Electrochemical tests were conducted using CR2016-type coin cells. The cells were assembled with the working electrode as prepared, lithium metal as anode, and Celgard 2300 film as separator in a glove-box filled with pure argon. The electrolyte solution was $1 \mathrm{M} \mathrm{LiPF} 6$ dissolved in ethylene carbonate (EC)/dimethyl carbonate (DMC)/diethyl carbonate (DEC) (1:1:1 by volume). Galvanostatic discharge/charge experiments were performed between 2.5 and 0.0 $\mathrm{V}$ at various constant current rates on a LAND CT2001A Battery Cycler (Wuhan, China). Lithium insertion into the working electrode was referred to as discharge, and the extraction as charge. The cell capacity was calculated based on the pure weight of active material.

Electrochemical impedance spectroscopy (EIS) was conducted in a three-electrode cell, in which lithium metal was used as both the counter and reference electrodes. The cells prepared as above were left to stand for several hours to equilibrate (SOC $=0$ ) before EIS measurements. The experiments were carried on a Solartron Instrument Model 1287 electrochemical interface and 1255B frequency response analyzer controlled by a computer. The frequency limits were set at $105-10^{-2} \mathrm{~Hz}$ with an ac oscillation of $5 \mathrm{mV}$. The EIS results were simulated by using ZPVIEW software.

\subsection{Thermal stability tests}

Electrode materials for differential scanning calorimetry (DSC) measurements were carried as follows. The cells were first discharged to a fully lithiated state and disassembled in a glove-box, then the obtained electrodes were dipped into DMC to remove residual $\mathrm{LiPF}_{6}$, Approximately $3 \mathrm{mg}$ of the electrode materials were scraped from the copper current-collector.

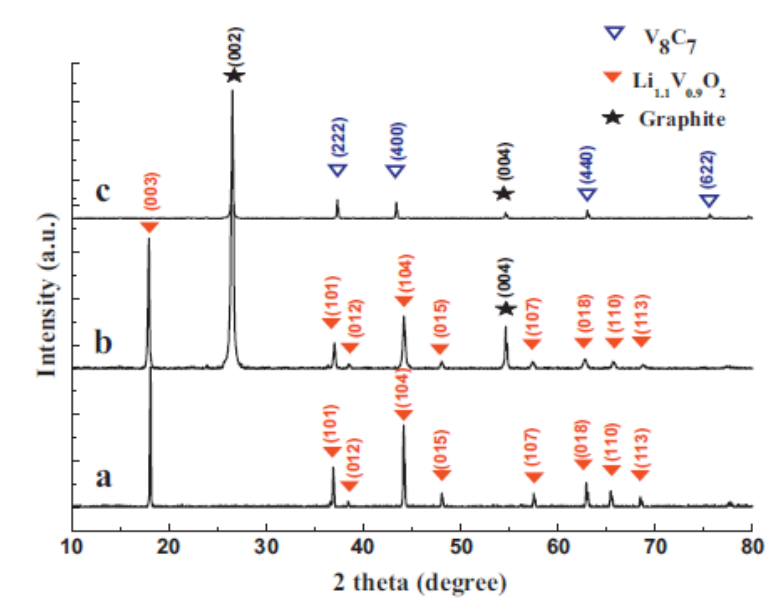

Fig. 1. X-ray diffraction patterns of: (a) P-LVO, (b) GA-LVO-1 and (c) GA-LVO-1100.

The obtained materials were hermetically sealed in gold-plated copper stainless steel capsules in the glove-box. The solid to electrolyte ratio was fixed at 1:2 
$(\mathrm{w} / \mathrm{w})$ to ensure the presence of excess electrolyte during the experiments. The DSC scans were performed using a DSC 200 F3 instrument (NETZSCH, Germany) with a scanning rate of $10^{\circ} \mathrm{C} \mathrm{min}^{-1}$. The masses of the DSC pans were measured before and after the DSC measurements to ensure that no leakage occurred during the experiments [7].

\section{Results and discussion}

The effect of synthesis temperature on the phase composition of the samples was firstly examined. In the previous studies, the P-LVO was prepared at 850 and $1100^{\circ} \mathrm{C}[3,4]$. Therefore, both GA-LVO-1 and P-LVO were prepared at $850^{\circ} \mathrm{C}$. The XRD pattern of P-LVO (Fig. 1a) prepared at $850^{\circ} \mathrm{C}$ was indexed to a hexagonal structure with the $\mathrm{R}-3 \mathrm{~m}$ space group, which is consistent with the previously reported results [3]. When graphite was added at $850{ }^{\circ} \mathrm{C}$, the diffraction line ascribed to $\mathrm{Li}_{1.1} \mathrm{~V}_{0.9} \mathrm{O}_{2}$, and graphite became visible (Fig. $1 \mathrm{~b}$ ), indicating that the presence of graphite did not affect the synthesis of the $\mathrm{Li}_{1.1} \mathrm{~V}_{\mathrm{O} .9} \mathrm{O}_{2}$ at $850{ }^{\circ} \mathrm{C}$. However, the XRD pattern for GA-LVO-110o (from the sample synthesized at $1100{ }^{\circ} \mathrm{C}$ ) (Fig. 1c) notably lacks the characteristic diffraction line ascribed to $\mathrm{Li}_{1.1} \mathrm{~V}_{\mathrm{O} .9} \mathrm{O}_{2}$ prepared at $1100{ }^{\circ} \mathrm{C}$ that was observable in previous reports [4]. The $\mathrm{XRD}$ instead shows a pattern characteristic of $\mathrm{V}_{8} \mathrm{C}_{7}$ (PDF: 35-0786), i.e., a reaction product of $\mathrm{V}_{2} \mathrm{O}_{3}$ and $\mathrm{C}$ under high temperature [8], which occurs via the following reaction:

$4 \mathrm{~V}_{2} \mathrm{O}_{3}(\mathrm{~s})+19 \mathrm{C}(\mathrm{s})=\mathrm{V}_{8} \mathrm{C}_{7}(\mathrm{~s})+12 \mathrm{CO}(\mathrm{g}) \uparrow$

Therefore, the preparation temperature of $850{ }^{\circ} \mathrm{C}$ was used in the following experiments.

Fig. 2 shows the morphologies of P-LVO synthesized without adding graphite, GALVO-1 synthesized via the in situ synthesis strategy at $850^{\circ} \mathrm{C}$ and MG-LVO prepared by ball-milling P-LVO and graphite together. The SEM images in Fig. 2a and b show that the $\mathrm{Li}_{1.1} \mathrm{~V}_{0.9} \mathrm{O}_{2}$ particles have a uniform size of approximately $1 \mu \mathrm{m}$ diameter and agglomerate into clusters. Fig. 2c and d shows that in the GA-LVO-1 sample, $\mathrm{Li}_{1.1} \mathrm{~V}_{\mathrm{O} .9} \mathrm{O}_{2}$ is anchored to the surface of graphite, which may achieve in the process of the melt of $\mathrm{Li}_{2} \mathrm{CO}_{3}$ following the reaction with $\mathrm{V}_{2} \mathrm{O}_{3}$. Whereas in the MG-LVO (Fig. 2e and f), the separated particles of $\mathrm{Li}_{1.1} \mathrm{~V}_{0.9} \mathrm{O}_{2}$ and graphite are clearly observed. These results indicate that the in situ synthesis strategy prevented the agglomeration of $\mathrm{Li}_{1.1} \mathrm{~V}_{0.9} \mathrm{O}_{2}$ and improved the contact between $\mathrm{Li}_{1.1} \mathrm{~V}_{\mathrm{O} .9} \mathrm{O}_{2}$ and graphite, which should lead to the improved electrochemical performance. 

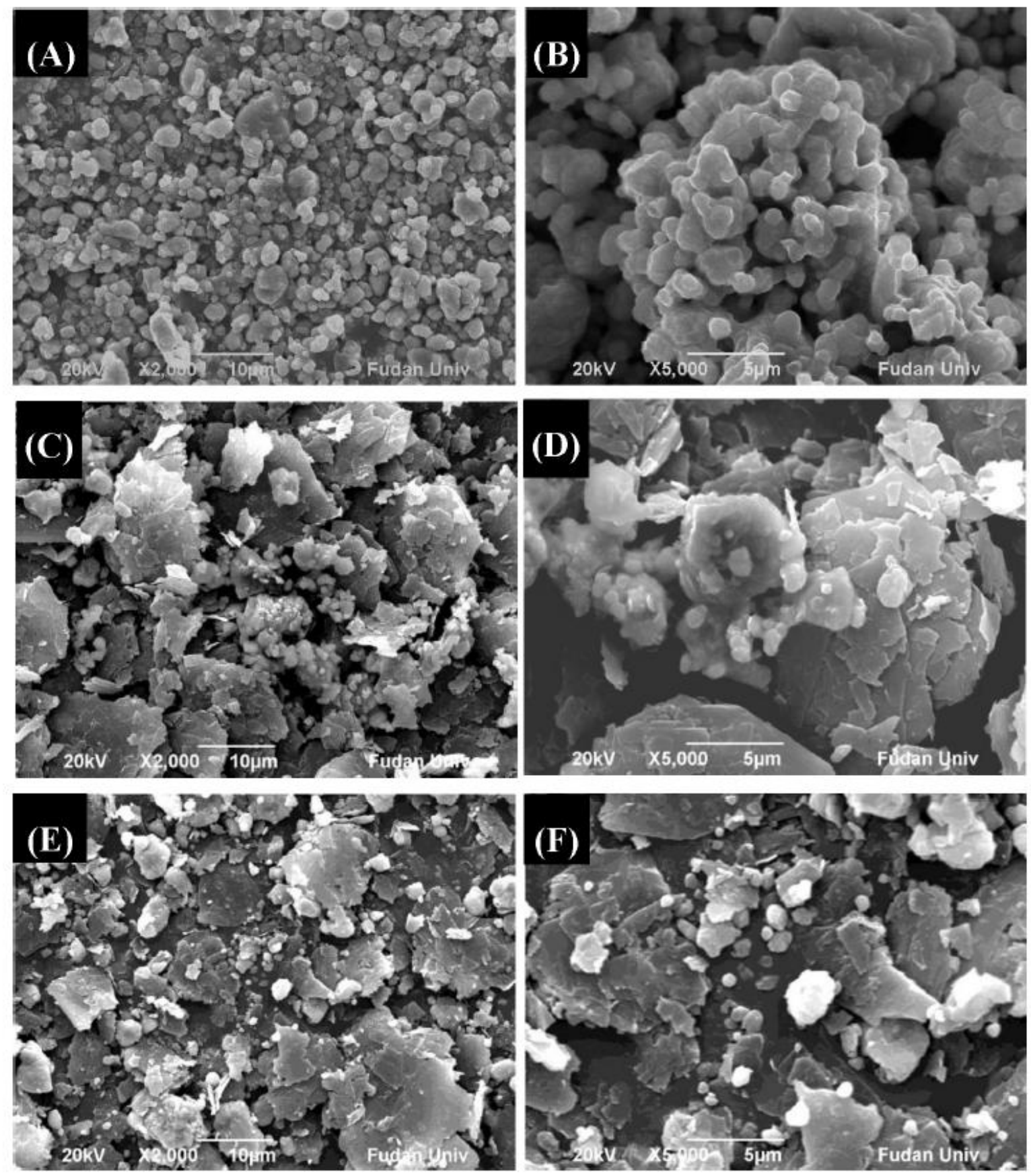

Fig. 2. SEM images of: (A and B) P-LVO, (C and D) GA-LVO-1 and (E and F) MG-LVO.

Fig. 3A and B show the first three discharge/charge curves of GA-LVO-1 and MGLVO at the rate of $0.1 \mathrm{C}$. The discharge capacity was $306 \mathrm{mAh} / \mathrm{g}$ for GA-LVO-1, with a reversible efficiency of $79 \%$. For comparison, the discharge capacity of the composite MG-LVO (prepared by ball-milling P-LVO and graphite at a 1:1 mass ratio) was 346 $\mathrm{mAh} / \mathrm{g}$ at $0.1 \mathrm{C}$, with a reversible efficiency of $72 \%$. Compared with GA-LVO-1, the lower reversible efficiency of MG-LVO may be due to the larger Li consumption on the formation of the solid electrolyte interface (SEI) and side reactions on the surface of the electrode. Fig. $3 \mathrm{C}$ shows the first three discharge/charge curves P-LVO, where the discharge and charge capacities of P-LVO were 309 and $192 \mathrm{mAh} / \mathrm{g}$, respectively (the theoretical specific capacity of $\mathrm{Li}_{1.1} \mathrm{~V}_{0.9} \mathrm{O}_{2}$ is $314 \mathrm{mAh} / \mathrm{g}$ [4]). The large irreversible capacity may have been caused by the following: (i) Li being trapped in a layered structure of $\mathrm{Li}_{1.1} \mathrm{~V}_{\mathrm{O} .9} \mathrm{O}_{2}$, (ii) $\mathrm{Li}$ consumption in the formation 
of SEI, and (iii) side reactions on the surface of the electrode, such as the reduction of electrolyte and contaminant $\left(\mathrm{H}_{2} \mathrm{O}\right.$ and $\left.\mathrm{O}_{2}\right)$ [9]. GA-LVO-1 showed better cycling stability compared with MG-LVO. The charge capacity of GA-LVO-1 was $232 \mathrm{mAh} / \mathrm{g}$ after 50 cycles at $0.1 \mathrm{C}$ (shown in Fig. 3D), with a corresponding capacity retentions of $96 \%$, whereas the charge capacity was $208 \mathrm{mAh} / \mathrm{g}$ for MG-LVO, with a corresponding capacity retention rate of $83 \%$. However, a sharp decay in the charge capacity for MG-LVO occurred before the tenth cycle, which is mainly attributed to volume change and the two-phase nature of the intercalation reaction [3]. Similar results were obtained for P-LVO (shown in Fig. 3D). The phenomenon of sharp decay was alleviated after the lithium vanadium oxide was anchored on the surface of the graphite, because graphite provides a support for the small particles derived from the electrochemical grinding with high electrical conductivity and enhances Li ion diffusion as well as capacity utilization. Consequently, the graphite-anchored lithium vanadium oxide prepared through the "one-pot" in situ synthesis strategy displayed the improved reversible capacity and cyclic performance.
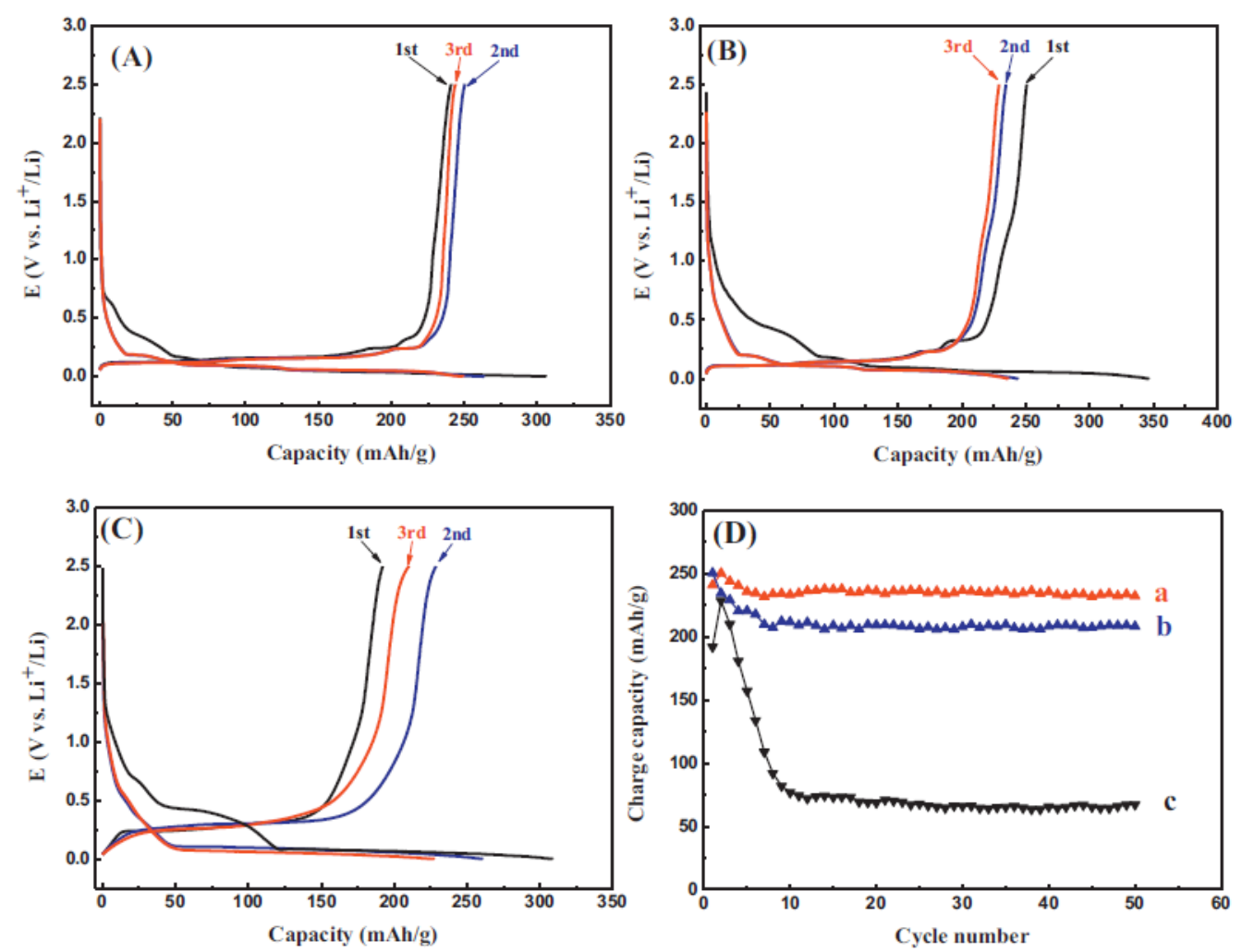

Fig. 3. The first three discharge/charge curves at $0.1 \mathrm{C}$ rate: (A) GA-LVO-1, (B) MG-LVO and (C) P-LVO; (D) the corresponding cyclic stability performance for the three above-mentioned samples: (a) GA-LVO-1, (b) MG-LVO and (c) P-LVO.

The rate performance of GA-LVO-1 and MG-LVO is shown in Fig. 4. The charge capacity for GA-LVO-1 was $219 \mathrm{mAh} / \mathrm{g}$ at $0.2 \mathrm{C}$ and $191 \mathrm{mAh} / \mathrm{g}$ at $0.5 \mathrm{C}$, while 194 and $136 \mathrm{mAh} / \mathrm{g}$ for MG-LVO, respectively. Compared with MG-LVO, the larger reversible capacity and superior cyclic performance of GA-LVO-1 may stem from the uniform distribution and anchoring of $\mathrm{Li}_{1.1} \mathrm{~V}_{\mathrm{O} .9} \mathrm{O}_{2}$ 


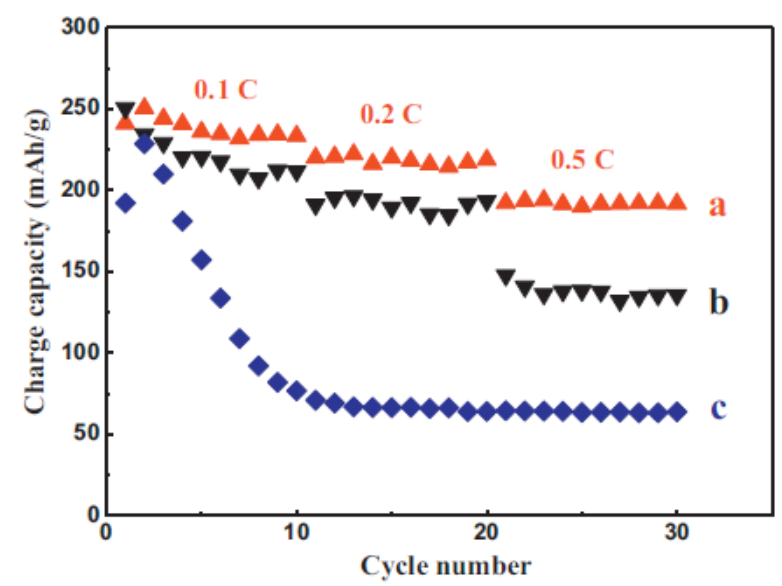

Fig. 4. The rate capability performance of $0.1,0.2$ and $0.5 \mathrm{C}$ for GA-LVO-1 (a), MGLVO (b) and (c) P-LVO.

In contrast to $\mathrm{Li}_{1.1} \mathrm{~V}_{0.9} \mathrm{O}_{2}$ agglomeration, the graphite-anchored lithium vanadium oxide increased the contact with graphite. Simultaneously, small particles created by the electrochemical grinding during cycling are supported on the surface of graphite and may enhance the rate capability and cyclic performance [5].

The graphite-anchored $\mathrm{Li}_{1.1} \mathrm{~V}_{0.9} \mathrm{O}_{2}$ provides the support for $\mathrm{Li}_{1.1} \mathrm{~V}_{0.9} \mathrm{O}_{2}$ during cycling, which is an important factor for improving electronic conductivity, cyclic and rate performance. Electronic conductivity and electrochemical resistance can be determined by electrochemical impedance measurements [10]. Fig. 5 shows the electrochemical impedance spectra of the prepared samples at open circuit potentials and the corresponding equivalent circuit. In the equivalent circuit, $R_{\mathrm{S}}$ is the ohmic resistance of the electrolyte and current collector, $\mathrm{Cdl}_{\mathrm{di}} \mathrm{Li}$, is the double-layer capacitance, and $R c t$ is the charge-transfer resistance at the bulk-electrolyte interface. $Z \mathrm{~W}$ relates to $\mathrm{Li}^{+}$diffusion in the inserted materials, and $\mathrm{Cint} \mathrm{Li}+$ relates to the insertion capacitance, reflecting the occupation of $\mathrm{Li}^{+}$in the inserted sites [11-13]. Fig. 5 shows that the experimental data (dots) fitted well with the equivalent circuit (the solid lines represent the fitted results). The resistance $(R \mathrm{ct})$ (obtained by fitting the equivalent circuit), which determines the charge transfer process of the lithium ion insertion/extraction reaction, is 20.7 and 23 Q for the GA-LVO-1 and MG-LVO, respectively. Compared with MG-LVO, the lower resistance confirms that the graphite-anchored lithium vanadium oxide has low charge-transfer resistance, which accounts for better reversible capacity and cyclic performance as anode of lithium ion battery.

The effect of the graphite content ratio to LVO (graphite: LVO) on the specific capacity and cycling performance of GA-LVO was also investigated. 


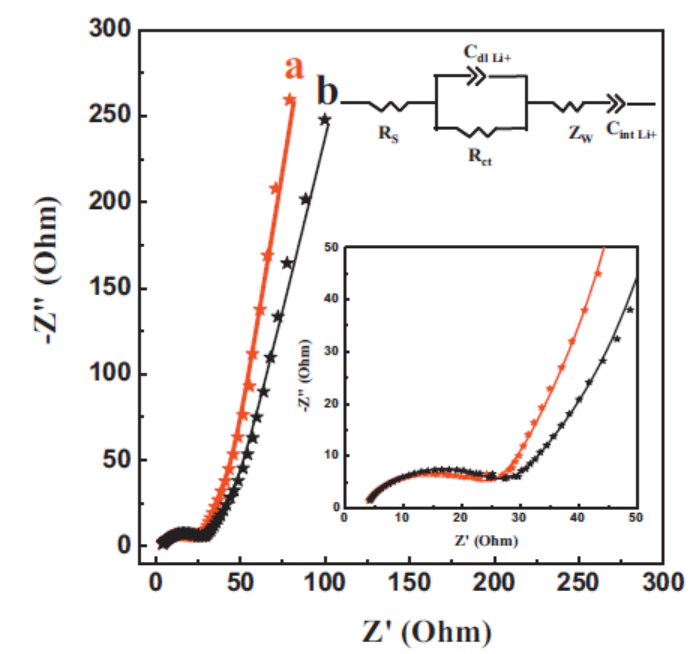

Fig. 5. Electrochemical impedance spectra of the as-prepared samples at open circuit potentials: (a) GA-LVO-1 and (b) MG- LVO, and the equivalent circuit and impedance spectra at high frequency are given in inset.

The calculated mass and volumetric capacity, reversible capacity and initial coulombic efficiency are summarized in Table 2. The cyclic performance of the three samples is shown in Fig. 6A. The charge capacity after 50 cycles was $96 \mathrm{mAh} / \mathrm{g}$ for GA-LVO-O.5, $232 \mathrm{mAh} / \mathrm{g}$ for GA-LVO-1 and $279 \mathrm{mAh} / \mathrm{g}$ for GA-LVO-2, corresponding to capacity retentions of $54 \%, 96 \%$ and $96 \%$. Fig. $6 \mathrm{~B}$ gives the rate capability of all three samples. At $0.2 \mathrm{C}$, the charge capacity was 82, 219 and $266 \mathrm{mAh} / \mathrm{g}$ for GALVO-0.5, GA-LVO-1 and GA-LVO-2, respectively. When the current rate was raised to $0.5 \mathrm{C}$, the charge capacity reduces into 29, 192 and $234 \mathrm{mAh} / \mathrm{g}$. All above finding indicates that the more content of the graphite content will have better reversible capacity and cyclic stability. As a final goal to obtain a high volumetric energy density electrode, LVO content should be adopted as high as possible, but this will reduce its cycling stability. Considering both the volumetric capacity and cycling stability, a mass ratio of graphite to LVO of 1:1 is selected.

Controlling the problem of thermal runaway in cells is vital for the commercial use of lithium ion batteries [14-16]. The DSC curves of the GA-LVO-1 and MG-LVO electrodes at a fully lithiated state are shown in Fig. 7. The exothermic peak at 104 and $135{ }^{\circ} \mathrm{C}$ for MG-LVO and GA-LVO-1 is due to the initial SEI film decomposition, and the lower exothermic peak and larger heat generation for MG-LVO compared with GA-LVO-1 is caused by the larger SEI film decomposition, which would account for the larger initial irreversible efficiency of $28 \%$ for MG-LVO compared with $21 \%$ for GA-LVO-1 [14,17]. A mild heat flow generation continued from $135{ }^{\circ} \mathrm{C}$ until a sharp exothermic peak appeared at $280{ }^{\circ} \mathrm{C}$ for both samples comes from the reaction of lithiated graphite with the electrolyte to form a new SEI [18]. 
Table 2

Comparision of calculated and experimental electrochemical performance of the as-prepared samples.

\begin{tabular}{llllll}
\hline Sample & \multicolumn{2}{l}{ Calculated } & & & Experimental \\
\cline { 2 - 3 } \cline { 5 - 6 } \cline { 5 - 6 } & $\begin{array}{l}\text { Mass } \\
\text { capacity } \\
(\mathrm{mAh} / \mathrm{g})\end{array}$ & $\begin{array}{l}\text { Volumetric } \\
\text { capacity } \\
\left(\mathrm{mAh} / \mathrm{cm}^{3}\right)\end{array}$ & & $\begin{array}{l}\text { Reversible } \\
\text { capacity } \\
(\mathrm{mAh} / \mathrm{g})\end{array}$ & $\begin{array}{l}\text { Initial } \\
\text { columbic } \\
\text { efficiency }(\%)\end{array}$ \\
\hline GA-LVO-2 & 353 & 902 & & 290 & 80 \\
GA-LVO-1 & 343 & 977 & & 241 & 79 \\
GA-LVO-0.5 & 333 & 1070 & & 178 & 70 \\
\hline
\end{tabular}
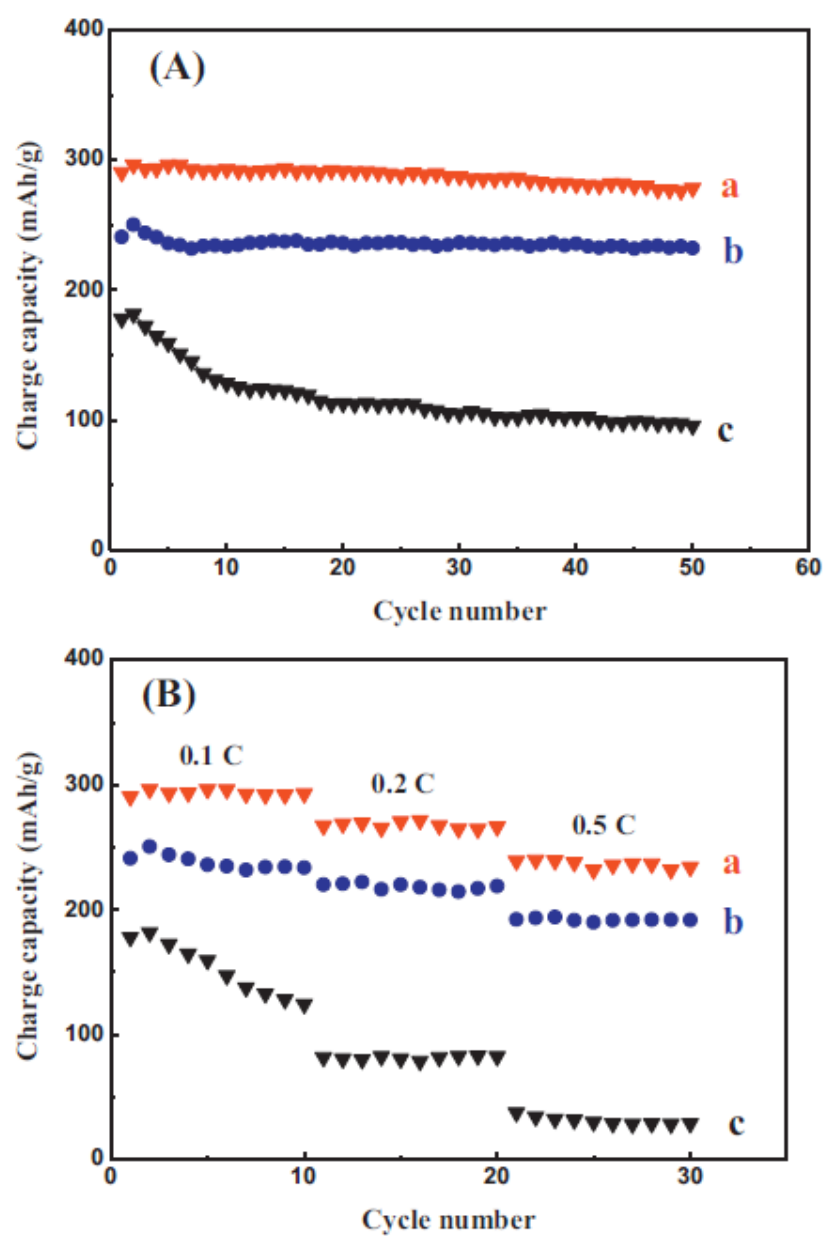

Fig. 6. Cycling stability tests (A) and rate capability performance (B) of GA-LVO composite with different ratios: (a) GA-LVO-2, (b) GA-LVO-1 and (c) GA-LVO-0.5. The cycling tests data were obtained from the cells cycling between 0 and $2.5 \mathrm{~V}$ at $0.1 \mathrm{C}$.

Meanwhile, a sharp exothermic peak was detected at 315 and $323{ }^{\circ} \mathrm{C}$ for MG-LVO and GA-LVO-1, respectively, which is attributed to the graphite structural collapse reaction between the graphite and the electrolyte [14]. 


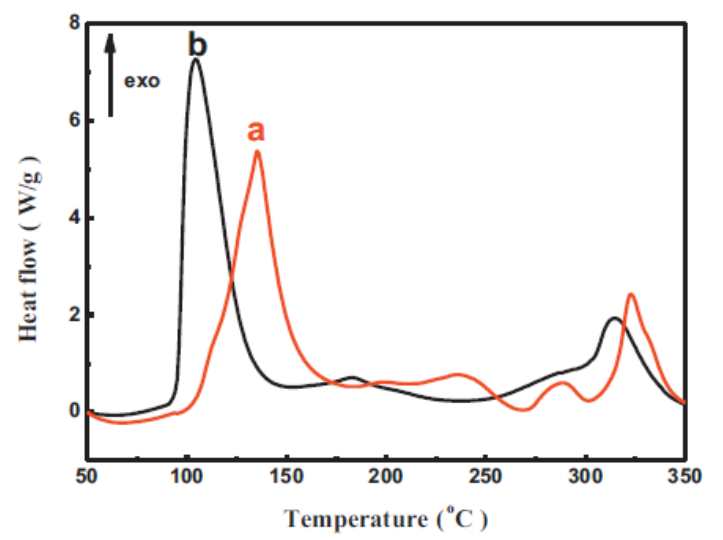

Fig. 7. DSC measurements of GA-LVO-1 (a) and MG-LVO (b) at fully lithiated states with $\mathrm{LPF}_{6}-\mathrm{EC} / \mathrm{DMC} / \mathrm{DEC}$ electrolyte. The experiment was carried in a sealed stainless steel capsule under $\mathrm{N}_{2}$ flow at a heating rate of $10^{\circ} \mathrm{C} \mathrm{min}^{-1}$.
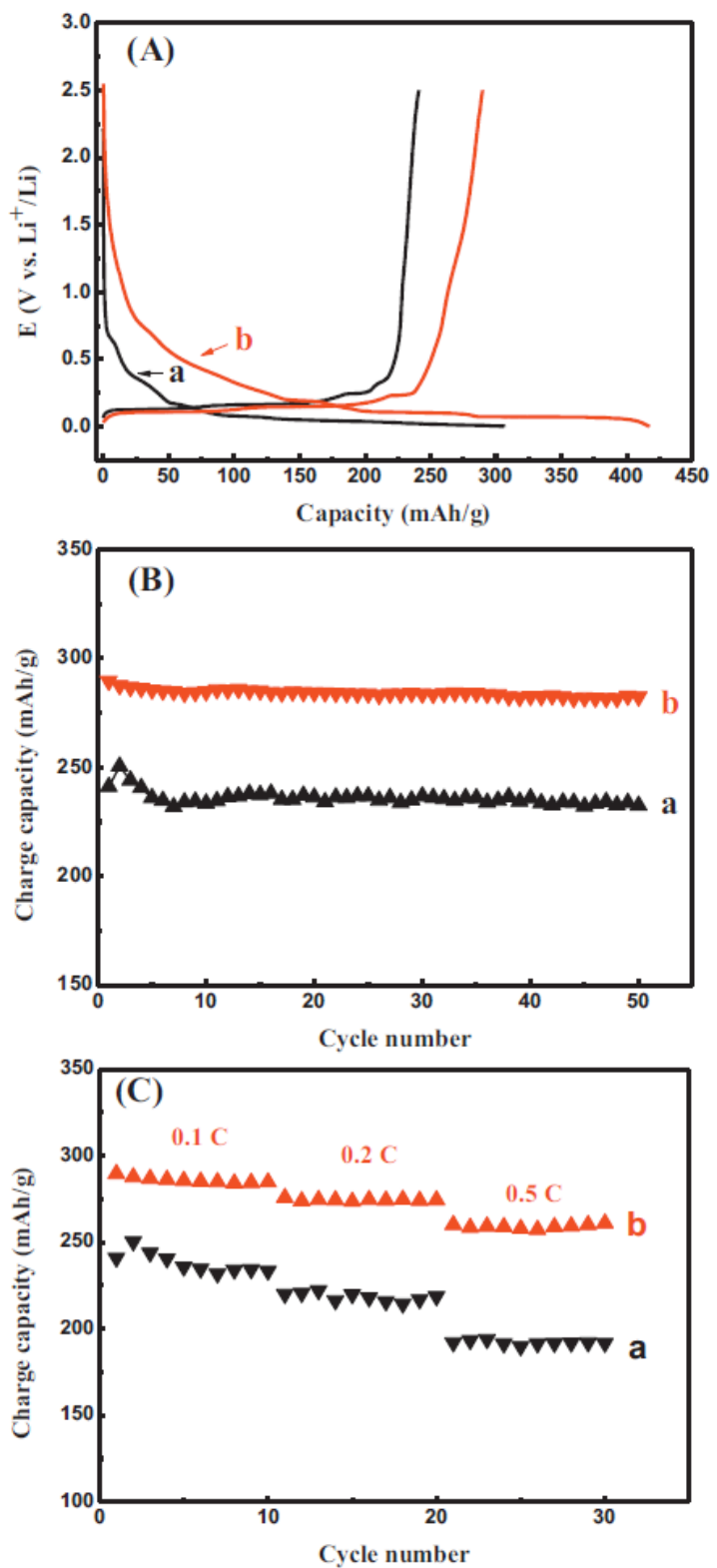

Fig. 8. The initial discharge/charge curves at $0.1 \mathrm{C}$ rate (A), cycling stability (B) and rate capability performance (C) of (a) GA-LVO-1 and (b) C-GA-LVO-1. 
From the above DSC results, compared with MG-LVO, the thermal stability of graphite-anchored lithium vanadium oxide has been improved with acceptable thermal stability for application as an anode material for lithium ion batteries.

Carbon coating is an important technology used to improve the electrochemical performance of electrode materials in lithium ion batteries. In this study, carbon coating was used to improve the reversible capacity and rate capability of GALVO-1. Fig. 8A shows that C-GA-LVO-1 had a high initial charge capacity of 290 $\mathrm{mAh} / \mathrm{g}$ with a reversible efficiency of 70\%. Compared with GA-LVO-1, thelarger irreversible efficiency may be due to larger Li consumption in the formation of the SEI after carbon coating. Fig. 8B shows the cycling stability performance of C-GALVO-1 after 50 cycles at $0.1 \mathrm{C}$. The charge capacity of C-GA-LVO-1 was $282 \mathrm{mAh} / \mathrm{g}$, with negligible capacity decay. The rate capability performance improved after using the carbon-coating technology (shown in Fig. 8C). At 0.2 and $0.5 \mathrm{C}$, the charge capacity was 274 and $260 \mathrm{mAh} / \mathrm{g}$. Compared with GA-LVO-1, the reversible capacity and rate capability at different rates were remarkable improved by increasing the electrical conductivity and enhancing the contact between $\mathrm{Li}_{1.1} \mathrm{~V}_{0.9} \mathrm{O}_{2}$ and graphite after carbon coating.

\section{Conclusions}

Graphite-anchored lithium vanadium oxide was successfully synthesized via a "one-pot" in situ method at an optimal synthesis temperature of $850{ }^{\circ} \mathrm{C}$. Synthesis at $1100{ }^{\circ} \mathrm{C}$ produced the by-product $\mathrm{V}_{8} \mathrm{C}_{7}$. The graphite-anchored lithium vanadium oxide had lower electrochemical resistance and better thermal stability than the composite prepared by mixing graphite and lithium vanadium oxide, which resulted in a larger reversible capacity, better cycling. Moreover, the carbon coated composite showed the significantly improved electrochemical performance with a reversible capacity of $282 \mathrm{mAh} / \mathrm{g}$ and negligible capacity decay after 50 cycles. The graphite-anchored lithium vanadium oxide described in the present work is an attractive candidate for anode material in lithium ion batteries.

\section{Acknowledgements}

This work was partially supported by the State Key Basic Research Program of PRC (2011CB935903), the National Natural Science Foundation of China (20925312), and Shanghai Science Technology Committee (o8DZ2270500). 


\section{References}

[1] J.Y. Luo, W.J. Cui, P. He, Y.Y. Xia, Raising the cycling stability of aqueous lithium-ion batteries by eliminating oxygen in the electrolyte, Nature Chemistry 2 (2010) 760 .

[2] J. Yi, X.P. Li, S.J. Hu, W.S. Li, L. Zhou, M.Q. Xu, J.F. Lei, L.S. Hao, Preparation of hierarchical porous carbon and its rate performance as anode of lithium ion battery, Journal of Power Sources 196 (2011) 6670.

[3] A.R. Armstrong, C. Lyness, P.M. Panchmatia, M.S. Islam, P.G. Bruce, The lithium intercalation process in the low-voltage lithium battery anode $\operatorname{Li}_{1}+\mathrm{x}$ $\mathrm{V}_{1}-\mathrm{x}_{2}$, Nature Materials 10 (2011) 223.

[4] N.S. Choi, J.S. Kim, R.Z. Yin, S.S. Kim, Electrochemical properties of lithium vanadium oxide as an anode material for lithium-ion battery, Materials Chemistry and Physics 116 (2009) 603.

[5] J.H. Song, H.J. Park, K.J. Kim, Y.N. Jo, J.S. Kim, Y.U. Jeong, Y.J. Kim, Electrochemical characteristics of lithium vanadate, $\mathrm{Li}_{1}+\mathrm{x} \mathrm{VO}_{2}$, new anode materials for lithium ion batteries, Journal of Power Sources 195 (2010) 6157.

[6] H.S. Kim, S.O. Kim, Y.T. Kim, J.K. Jung, B.K. Na, J.K. Lee, Electrochemical properties of Li1.1 Vo.75 Wo.075 Moo.075 O2 /graphite composite anodes for lithium-ion batteries, Bulletin of Korean Chemical Society 33 (2012) 65 .

[7] W.J. Cui, J. Yi, L. Chen, C.X. Wang, Y.Y. Xia, Synthesis and electrochemical characteristics of NASICON-structured $\mathrm{LiSn}_{2}\left(\mathrm{PO}_{4}\right)_{3}$ anode material for lithium-ion batteries, Journal of Power Sources 217 (2012) 77.

[8] Z.W. Zhao, Y. Liu, H. Cao, S.J. Gao, M.J. Tu, Phase evolution during synthesis of vanadium carbide $\left(\mathrm{V}_{8} \mathrm{C}_{7}\right)$ nanopowders by thermal processing of the precursor, Vacuum 82 (2008) 852.

[9] P. Arora, R.E. White, M. Doyle, Capacity fade mechanisms and side reactions in lithium-ion batteries, Journal of the Electrochemical Society 145 (1998) 3647.

[10] G.N. Zhu, C.X. Wang, Y.Y. Xia, A comprehensive study of effects of carbon coating on $\mathrm{Li}_{4} \mathrm{Ti}_{5} \mathrm{O}_{12}$ anode material for lithium-ion batteries, Journal of the Electrochemical Society 158 (2011) A102.

[11] M.D. Levi, D. Aurbach, Simultaneous measurements and modeling of the electrochemical impedance and the cyclic voltammetric characteristics of graphite electrodes doped with lithium, Journal of Physical Chemistry B 101 (1997) 4630.

[12] M.D. Levi, D. Aurbach, Diffusion coefficients of lithium ions during intercalation into graphite derived from the simultaneous measurements and modeling of electrochemical impedance and potentiostatic intermittent titration characstics of thin graphite electrodes, Journal of Physical Chemistry B 101 (1997) 4641.

[13] D.S. Lu, W.S. Li, X.X. Zuo, Z.Z. Yuan, Q.M. Huang, Study on electrode kinetics of $\mathrm{Li}+$ insertion in $\mathrm{Lix}_{2} \mathrm{Mn}_{2} \mathrm{O}_{4}(\mathrm{o} \leq \mathrm{x} \leq 1)$ by electrochemical impedance spectroscopy, Journal of Physical Chemistry C 111 (2007) 12067.

[14] Y.S. Park, H.J. Bang, S.M. Oh, Y.K. Sun, S.M. Lee, Effect of carbon coating on thermal stability of natural graphite spheres used as anode materials in lithium-ion batteries, Journal of Power Sources 190 (2009) 553. 
[15] Y.T. Lee, C.S. Yoon, J. Prakash, Y.K. Sun, Effect of Li-doping on electrochemical performance of natural graphite anode for lithium secondary batteries, Journal of the Electrochemical Society 151 (2004) A1728.

[16] Q.M. Pan, K.K. Guo, L.Z. Wang, S.B. Fang, Novel modified graphite as anode material for lithium-ion batteries, Journal of the Electrochemical Society 149 (2002) A1218.

[17] H. Yang, H. Bang, K. Amine, J. Prakash, Investigations of the exothermic reactions of natural graphite anode for Li-ion batteries during thermal runaway, Journal of the Electrochemical Society 152 (2005) A73.

[18] J. Yamaki, H. Takatsuji, T. Kawamura, M. Egashira, Thermal stability of graphite de with electrolyte in lithium-ion cells, Solid State Ionics 148 (2002) 241. 